\title{
Bekendmaking besluit 'op een andere geschikte wijze'
}

\author{
Rolf Ortlep
}

\author{
Aanbevolen citeerwijze bij dit artikel \\ Rolf Ortlep, 'Bekendmaking besluit 'op een andere geschikte wijze", Netherlands \\ Administrative Law Library, december 2013, DOI: 10.5553/NALL/.000016
}

\section{Inleiding}

Op 1 januari 1998 is de derde tranche van de Algemene wet bestuursrecht (Awb) in werking getreden. ${ }^{\mathbf{1}}$ Hierdoor zijn wat betreft de bekendmaking van besluiten de artikelen 3:41 en 3:42 Awb gewijzigd. In deze bijdrage wordt uitsluitend de aandacht gevestigd op de wijziging van artikel 3:41 Awb, aangezien daarover relatief weinig geschreven is. ${ }^{\mathbf{2}}$ Uit het eerste lid van dat artikel volgt dat besluiten die tot een of meer belanghebbenden zijn gericht bekend worden gemaakt door toezending of uitreiking aan hen, met inbegrip van de aanvrager. Door de inwerkingtreding van de derde tranche Awb is aan artikel 3:41 een tweede lid toegevoegd, dat luidt: 'Indien de bekendmaking van het besluit niet kan geschieden op de wijze als voorzien in het eerste lid, geschiedt zij op een andere geschikte wijze.' Bij het - in het kader van de derde tranche - ontwerpen van de afdeling over bestuursdwang kwam bij de regering het inzicht dat bekendmaking door toezending of uitreiking van de beslissing tot bestuursdwang praktisch niet altijd mogelijk is, omdat de identiteit van de overtreder bij het bestuursorgaan onbekend is of het bestuursorgaan niet beschikt over een (correct) adres. Dit werd als een algemeen probleem gezien, in de zin dat dit zich ook kon voordoen bij bekendmaking van andere besluiten. Om deze reden is aan artikel 3:41 Awb het hierboven genoemde tweede lid toegevoegd. 3 De vraag die in deze bijdrage centraal staat is of door artikel 3:41, tweede lid, Awb een oplossing is gecreëerd voor het probleem dat bij bekendmaking van het besluit de identiteit van de belanghebbende bij het bestuursorgaan onbekend is of het bestuursorgaan niet beschikt over een (correct) adres? De opbouw van deze bijdrage is als volgt. Nadat in paragraaf 2 de bekendmaking van het besluit in het algemeen is besproken, wordt in paragraaf 3 de jurisprudentie over artikel 3:41, tweede lid, Awb behandeld. Vervolgens wordt over dit onderwerp in paragraaf 4 een blik op de toekomst gegeven. Paragraaf 5 sluit deze bijdrage af met een conclusie.

\section{Bekendmaking}

Op grond van artikel 6:8, eerste lid, Awb vangt de termijn voor het indienen van een bezwaar- of beroepschrift aan met ingang van de dag ná die waarop het besluit op de voorgeschreven wijze is bekendgemaakt. De woorden 'op de 
voorgeschreven wijze' verwijzen wat betreft het besluit naar de artikelen 3:41 en 3:42 Awb. 4 Vanwege het feit dat hiermee de Awb een eigen stelsel kent van procedurele bepalingen over bekendmaking van besluiten wordt een beroep op bijvoorbeeld artikel 3:37 Burgerlijk Wetboek (BW), dat ziet op de vorm en werking van wilsverklaringen en andere mededelingen, door de bestuursrechter verworpen. 5

Het 'op de voorgeschreven wijze' bekendmaken van het besluit is weliswaar noodzakelijk voor de aanvang van de termijn voor het indienen van een bezwaar- of beroepschrift, maar naar de letter genomen, vergelijk hieronder, niet of het bekend is gemaakt en daarmee in overeenstemming met artikel 3:40 Awb in werking is getreden. In dat artikel is slechts bepaald dat het besluit niet in werking treedt voordat het is bekendgemaakt. ${ }^{6}$ Anders gezegd, ondanks dat het besluit wel tot stand is gekomen blijven de rechtsgevolgen latent tot aan bekendmaking. Het moment van de bekendmaking dient dan ook onderscheiden te worden van het moment van de totstandkoming van het besluit. ${ }^{7}$ Uit de uitspraak van de Afdeling bestuursrechtspraak van de Raad van State (ABRvS) van 2 juli $2008^{\mathbf{8}}$ volgt dat het besluit in de regel tot stand is gekomen wanneer de besluitvorming is voltooid en de beslissing is verwoord in een ondertekend 9 en van dagtekening voorzien geschrift. De bekendmaking - op de voorgeschreven wijze - is aldus voor de totstandkoming van het besluit niet constitutief. ${ }^{\mathbf{1 0}}$

Met artikel 3:40 Awb wordt uitdrukking gegeven aan de - uit het formele rechtszekerheidsbeginsel voortvloeiende - rechtsregel dat een rechtssubject alleen aan het recht gebonden kan zijn wanneer hij daarvan kennis heeft genomen of redelijkerwijs had kunnen nemen. ${ }^{\mathbf{1 1}}$ Anders dan in artikel 6:8, eerste lid, Awb, wordt, zoals hierboven is gezegd, in artikel 3:40 Awb niet gesproken van de eis dat het besluit 'op de voorgeschreven wijze' bekend moet zijn gemaakt, maar slechts dat het besluit bekend moet zijn gemaakt wil het inwerkingtreden. Daarentegen valt uit de parlementaire geschiedenis af te leiden dat ook bij artikel 3:40 op bekendmaking van het besluit 'op de voorgeschreven wijze' en daarmee op de artikelen 3:41 en 3:42 Awb wordt gedoeld. ${ }^{12}$ Dit komt ook in de jurisprudentie, zij het impliciet, tot uitdrukking. Zo heeft het College van Beroep voor het bedrijfsleven (CBb) in zijn uitspraak van 18 januari 2013 als volgt overwogen:

\footnotetext{
'Volgens artikel 3:40 Awb treedt een besluit niet in werking voordat het is bekendgemaakt. Gelet op artikel 3:41 Awb wordt een besluit - in een geval als het onderhavige - bekend gemaakt door toezending aan de belanghebbende. ${ }^{13}$
}

Gelet op het bovenstaande zijn de artikelen 3:41 en 3:42 Awb bepalend voor de bekendmaking en inwerkingtreding van het besluit (artikel 3:40 Awb), alsmede voor de aanvang van de termijn voor het indienen van een bezwaar- of beroepschrift (artikel 6:8, eerste lid, Awb). In de marge zij opgemerkt dat voor de inwerkingtreding van het besluit en de aanvang van de termijn voor het indienen van een bezwaar- of beroepschrift een afwijkend regiem kan gelden. Ter illustratie van het laatste kan gewezen worden op artikel 22j Algemene wet inzake rijksbelastingen (Awr). Uit dat artikel volgt dat de termijn voor het indienen van een bezwaarschrift aanvangt met ingang van de dag ná die van dagtekening van een aanslagbiljet of van het afschrift van een voor bezwaar vatbare beschikking, tenzij de dag van dagtekening gelegen is vóór de dag van de 
bekendmaking. Een soortgelijke bepaling is artikel 26c Awr voor de termijn voor het indienen van een beroepschrift. ${ }^{\mathbf{4}}$

\section{Bekendmaking op een andere geschikte wijze}

Uit het eerste lid van artikel 3:41 Awb volgt dat besluiten die tot een of meer belanghebbenden zijn gericht bekend worden gemaakt door toezending of uitreiking aan hen, met inbegrip van de aanvrager. Als de bekendmaking van het besluit niet kan geschieden door toezending of uitreiking, dient het krachtens artikel 3:41, tweede lid, Awb op een andere geschikte wijze te geschieden. Zoals in de inleiding is besproken, heeft dat tweede lid als doel om een oplossing te creëren voor het probleem dat bij bekendmaking van het besluit de identiteit van de belanghebbende bij het bestuursorgaan onbekend is of het bestuursorgaan niet beschikt over een (correct) adres. Uit de parlementaire geschiedenis blijkt dat bij het begrip 'op een andere geschikte wijze' gedacht kan worden aan publicatie in een dag- of nieuwsblad, aanplakking op het gemeentelijk publicatiebord, of aanplakking ter plekke. ${ }^{\mathbf{1 5}}$ Onder dat begrip valt blijkens de jurisprudentie tevens toezending van het besluit aan de moeder van de belanghebbende, welke laatste geen vaste woon- of verblijfsplaats heeft ${ }^{\mathbf{1 6}}$; het uitreiken van het besluit bij het ophalen van een - met toepassing van bestuursdwang - verwijderde fiets ${ }^{\mathbf{1 7}}$; het mededelen van het besluit in de Staatscourant bij het onbekend zijn van een vaste woon- of verblijfsplaats van de belanghebbende ${ }^{\mathbf{1 8}}$, en plaatsing van de integrale tekst van het (onteigenings)besluit (van de effecten en vermogensbestanddelen van SNS REAAL N.V. en SNS Bank N.V) op de website van het Ministerie van Financiën als het gaat om een zeer groot aantal en veelal onbekende belanghebbenden ${ }^{\mathbf{1 9}}$.

Een enigszins aparte categorie betreft de jurisprudentie over de vraag of toezending van het besluit naar het laatst bekende adres van de belanghebbende valt onder het begrip 'op een andere geschikte wijze' ex artikel 3:41, tweede lid, Awb? In de jurisprudentie wordt deze vraag verschillend beantwoord: enerzijds is er jurisprudentie waarin is uitgemaakt dat toezending naar het laatst bekende adres van de belanghebbende valt onder het begrip 'op een andere geschikte wijze' ${ }^{\mathbf{2 0}}$, anderzijds komt in de jurisprudentie tot uitdrukking dat onder het begrip 'toezending' ex artikel 3:41, eerste lid, Awb tevens toezending naar het laatst bekende adres van de belanghebbende valt ${ }^{\mathbf{2 1}}$. Uit deze jurisprudentie volgt tevens dat toezending van het besluit naar het laatst bekende adres van de belanghebbende ook geldt als bekendmaking indien het bestuursorgaan weet of redelijkerwijs had kunnen weten dat dit adres niet (meer) het adres van de belanghebbende is en deze laatste heeft nagelaten het bestuursorgaan van een adreswijziging op de hoogte te stellen. ${ }^{\mathbf{2 2}}$ Op het eerste gezicht wringt deze jurisprudentie met de - uit het formele rechtszekerheidsbeginsel voortvloeiende - rechtsregel, vergelijk paragraaf 2, dat een rechtssubject alleen aan het recht gebonden kan zijn wanneer hij daarvan kennis heeft genomen of redelijkerwijs had kunnen nemen. Hiertegen kan evenwel worden ingebracht dat de belanghebbende van het besluit redelijkerwijs kennis had kunnen nemen door een adreswijziging aan het bestuursorgaan door te geven. ${ }^{\mathbf{2 3}}$ Daarbij komt dat er dienaangaande voor de belanghebbende een gunstig regiem is ontstaan, omdat een aan de gemeente doorgegeven adreswijziging na verwerking in het Gemeentelijke Basisadministratie Persoonsgegevens (GBA) voor verschillende andere overheden toegankelijk is, zoals de belastingdienst en ministeries. ${ }^{\mathbf{2 4}}$ 
'toezending' ex artikel 3:41, eerste lid, Awb tevens toezending naar het laatst bekende adres van de belanghebbende valt de vaste lijn wordt, dan is daarmee de invoering van het tweede lid van artikel 3:41 Awb voor een deel overbodig gebleken. In dat geval is de toegevoegde waarde van dat lid niet (langer) gelegen om een oplossing te bieden voor de situatie dat het bestuursorgaan niet beschikt over het correcte adres van de belanghebbende, maar heeft het alleen toegevoegde waarde om een oplossing te bieden voor de volgende situaties: het bestuursorgaan beschikt in het geheel niet over een adres van de belanghebbende, of de identiteit van de belanghebbende is bij het bestuursorgaan onbekend, al dan niet in combinatie met dat het een zeer groot aantal belanghebbenden betreft.

\section{De toekomst}

Het is geen voorzichtige voorspelling dat in de toekomst de regel gaat worden dat het besluit elektronisch bekend wordt gemaakt. In de huidige tekst van de Awb is te wijzen op afdeling 2.3 Awb, meer hier in het bijzonder op artikel 2:14, eerste lid, Awb. Daarin is bepaald dat het bestuursorgaan een bericht dat tot een of meer geadresseerden is gericht elektronisch kan verzenden voor zover de geadresseerde kenbaar heeft gemaakt dat hij langs deze weg voldoende bereikbaar is. ${ }^{\mathbf{2 5}}$ Hoewel hierdoor thans nog het uitgangspunt is 'niet digitaal verkeer, tenzij', zijn er in het kader van de effectiviteit (en kostenbesparing) bijzondere bestuurswetten en (wetgevings)initiatieven tot stand gebracht waarin, met uitdrukkelijke afwijking van artikel 2:14, eerste lid Awb, verplichtingen tot digitaal verkeer zijn opgenomen. ${ }^{\mathbf{2 6}}$ De gedachten gaan daarbij uit naar het bekendmaken van besluiten via de elektronische weg in combinatie met een beveiligde internetportal, zoals thans 'MijnOverheid', 'Mijn SVB' en 'Mijn DUO' (voorheen: 'Mijn IB-Groep'). Van deze laatste internetportal is inmiddels uit de jurisprudentie gebleken dat dit als volgt werkt. De belanghebbende kan er voor kiezen om berichten over studiefinanciering elektronisch te ontvangen door de door DUO (voorheen: IB-Groep) gehanteerde Algemene Voorwaarden (AV) te aanvaarden. Indien de belanghebbende daarvoor kiest, brengt dat met zich mee dat het bericht (besluit) studiefinanciering in beginsel niet langer per reguliere post wordt verzonden, maar het te raadplegen is op de website 'Mijn DUO'. Volgens artikel 3, derde lid, AV wordt de belanghebbende, zodra een nieuw bericht (besluit) studiefinanciering beschikbaar is op de website, door middel van een emailbericht - aan het door de belanghebbende opgegeven emailadres - hierop geattendeerd. Het verzenden van het emailbericht wordt beschouwd als de verzending en bekendmaking van het bericht (besluit) studiefinanciering. Als het emailbericht na meerdere pogingen onbestelbaar retour komt, wordt de belanghebbende als onvoldoende bereikbaar langs die weg beschouwd en wordt het bericht (besluit) studiefinanciering binnen drie weken ná de elektronische verzending alsnog per reguliere post verzonden. De datum waarom het bericht (besluit) studiefinanciering is geplaatst op 'Mijn DUO' is het moment van bekendmaking in de zin van artikel 3:41 Awb. Ingevolge artikel 6:8, eerste lid, Awb vangt de termijn voor het indienen van een bezwaar- of beroepschrift tegen het bericht (besluit) studiefinanciering aan met ingang van de dag ná die waarop het besluit op de voorgeschreven wijze is bekendgemaakt, derhalve met ingang van de dag ná plaatsing ervan op 'Mijn DUO'. ${ }^{27}$

\section{Conclusie}

Zoals in de inleiding is weergegeven, staat in deze bijdrage de volgende vraag 
centraal: is door artikel 3:41, tweede lid, Awb een oplossing gecreëerd voor het probleem dat bij bekendmaking van het besluit de identiteit van de belanghebbende bij het bestuursorgaan onbekend is of het bestuursorgaan niet beschikt over een (correct) adres? Deze vraag kan positief worden beantwoord. In de jurisprudentie komt tot uitdrukking dat in de praktijk verschillende oplossingen zijn gevonden om het besluit 'op een andere geschikte wijze' ex artikel 3:41, tweede lid, Awb bekend te maken. In zoverre heeft de derde tranche een stimulans gegeven om tot dergelijke oplossingen te komen. Uit de jurisprudentie komt evenwel ook naar voren dat onder het begrip 'toezending' ex artikel 3:41, eerste lid, Awb tevens toezending naar het laatst bekende adres van de belanghebbende valt. Wanneer die jurisprudentie de vaste lijn wordt, dan is daarmee de invoering van het tweede lid van artikel 3:41 Awb voor een deel overbodig gebleken. In dat geval is de toegevoegde waarde van dat lid niet (langer) gelegen om een oplossing te bieden voor de situatie dat het bestuursorgaan niet beschikt over het correcte adres van de belanghebbende, maar heeft het alleen toegevoegde waarde om een oplossing te bieden voor de volgende situaties: het bestuursorgaan beschikt in het geheel niet over een adres van de belanghebbende, of de identiteit van de belanghebbende is bij het bestuursorgaan onbekend, al dan niet in combinatie met dat het een zeer groot aantal belanghebbenden betreft.

\section{Noten}

1 Wet van 20 juni 1996, Stb. 1996, 333, tot aanvulling van de Algemene wet bestuursrecht (Derde tranche Algemene wet bestuursrecht). Inwerkingtreding: 1 januari 1998 (Stb. 1997, 581).

2 Zij wat betreft (de wijzing van) artikel 3:42 Awb bijvoorbeeld gewezen op M.M. Groothuis, 'Op weg naar een digitale overheid. Over waarborgen en randvoorwaarden in bestuursrechtelijk perspectief', Gst. 2013/82, p. 436-445; M.M. Groothuis, 'Het voorontwerp Elektronisch verkeer met de bestuursrechter en het wetsvoorstel Elektronische bekendmaking. Over kansen en knelpunten voor de digitale overheid', NTB 2008, p. 167-175 inclusief verwijzingen.

3 Vergelijk PG Awb III, p. 149 en p. 366 e.v.

4 Vergelijk PG Awb I, p. 294. Zie daarbij tevens artikel 7:12, tweede lid, en artikel 7:26, derde lid, Awb.

5 Vergelijk CRvB 6 augustus 2013, ECLI:NL:CRVB:2013:1299. Verder CRvB 4 december 1997, TAR 1998/26; JB 1998/39.

6 De bekendmaking zelf is geen besluit, 'nu de bekendmaking', aldus de ABRvS (20 april 2011, $A B$ 2011/140, m.nt. Van Hall), 'niet is gericht op rechtsgevolg, maar slechts leidt tot inwerkingtreding van rechtsgevolgen die het besluit zelf beoogt in het leven te roepen'.

7 Vergelijk R. Ortlep, 'Het besluitbegrip: een verdampende theorie', RMThemis 2008, p. 243-252 inclusief verwijzingen.

8 ABRvS 2 juli 2008, $A B$ 2008/278, m.nt. Ortlep.

9 Dit is anders in het geval van een geautomatiseerd aangemaakte brief. 
Vergelijk ABRvS 7 april 2010, $A B$ 2010/151, m.nt. Van Hall; ABRvS 10 maart 2004, $A B$ 2004/314, m.nt. Den Ouden.

10 Vergelijk HR 29 juni 2012, $A B$ 2012/276, m.nt. Ortlep; ABRvS 22 mei 2001, $A B$ 2002/117.

11 Vergelijk J.G. Steenbeek, Rechtshandeling en rechtsgevolg in het Staats- en administratief recht, Arnhem: Vuga 1958, p. 50-51. Verder PG Awb I, p. 231. Zie HR 19 november 1948, NJ 1949/86, m.nt. Houwing; AB 1949, p. 277; HR 4 november 1949, $A B$ 1950, p. 178; HR 4 december 1985, NJ 1986/668, m.nt. Scheltema; $A B$ 1986/277, m.nt. Van der Burg.

12 Vergelijk PG Awb I, p. 231 e.v.

13 Vergelijk CBb 18 januari 2013, ECLI:NL:CBB:2013:BZ3253. Verder ABRvS 22 februari 2006, $A B$ 2006/199, m.nt. Verheij.

14 Vergelijk tevens artikel 35 en artikel 36 Algemene wet inkomensafhankelijke regelingen.

15 PG Awb III, p. 149. Vergelijk ABRvS 1 mei 2013, zaaknr. 201206704/1/A3; ABRvS 24 februari 2010, JB 2010/103; ABRvS 12 november 2008, JB 2009/30; HR 1 maart 2000, BNB 2000/169, m.nt. Snoijink; JB 2000/87, m.nt. NiessenCobben.

16 Vz. ABRvS 29 november 2001, $A B$ 2002/214, m.nt. Marseille.

17 ABRvS 9 februari 2005, $A B$ 2005/226, m.nt. Wertheim.

18 ABRvS 19 oktober 2011, zaaknr. 201104221/1/V6; ABRvS 4 december 2007, $J V$ 2008/49; ABRvS 18 april 2007, JV 2007/285.

19 ABRvS 25 februari 2013, $A B$ 2013/146, m.nt. Jansen.

20 Vergelijk CBb 29 februari 2012, ECLI:NL:CBB:2012:BV8249; ABRvS 1 februari 2012, zaaknr. 201103818/1/A3; CRvB 5 augustus 2011, ECLI:NL:CRVB:2011:BR4299; ABRvS 15 juli 2009, JV 2009/354; ABRvS 23 juni 2008, zaaknr. 200800298/1; CRvB 9 april 2007, JWWB 2007/162; RSV 2007/179; ABRvS 29 maart 2006, JB 2006/146, m.nt. Overkleeft-Verburg; ABRvS 1 juni 2005, $A B$ 2005/443 m.nt. Sewandono.

21 Vergelijk CRvB 26 november 2013, ECLI:NL:CRVB:2013:2554; CRvB 21 mei 2013, ECLI:NL:CRVB:2013:CA0963; CRvB 9 april 2013, ECLI:NL:CRVB:2013:BZ6710; CRvB 4 december 2012, ECLI:NL:CRVB:2012:BY5021; CRvB 8 juli 2008, ECLI:NL:CRVB:2008:BD8215. Zie CRvB 10 december 2013, ECLI:NL:CRVB:2013:2762; CRvB 11 september 2013, ECLI:NL:CRVB:2013:1753; CRvB 21 juni 2011, ECLI:NL:CRVB:2011:BRo473; CRvB 8 juni 2011, ECLI:NL:CRVB:2011:BQ9034; CRvB 26 oktober 2010, ECLI:NL:CRVB:2010:BO1872; CRvB 10 september 2010, ECLI:NL:CRVB:2010:BN7801; CRvB 13 juli 2010, USZ 2010/281; CRvB 1 september 2009, ECLI:NL:CRVB:2009:BJ7888. Verder CRvB 13 augustus 2002, USZ 2002/290. 
22 Vergelijk CRvB 26 november 2013, ECLI:NL:CRVB:2013:2554; CRvB 21 mei 2013, ECLI:NL:CRVB:2013:CA0963; CRvB 21 juni 2011, ECLI:NL:CRVB:2011:BRo473; CRvB 26 oktober 2010, ECLI:NL:CRVB:2010:BO1872; CRvB 13 juli 2010, USZ 2010/281; CRvB 1 september 2009, ECLI:NL:CRVB:2009:BJ7888.

23 Het (fiscale) bestuursrecht mist een wettelijke bepaling voor de wijze waarop een adreswijziging moet worden doorgegeven. Vergelijk HR 13 juli 2012, $A B$ 2013/381, m.nt. Ortlep; BNB 2012/263, m.nt. Pechler.

24 Vergelijk HR 23 november 2007, $A B$ 2008/92, m.nt. De Waard; $B N B$ 2008/30, m.nt. Van Leijenhorst; ABRvS 20 augustus 2008, $A B$ 2008/342, m.nt. Wertheim; JB 2008/219; ABRvS 29 februari 2012, $A B$ 2012/209, m.nt. De Waard.

25 Vergelijk CRvB 14 oktober 2010, JB 2010/281; TAR 2011/8.

26 Vergelijk M.M. Groothuis 2013, p. 436-445 inclusief verwijzingen.

27 Vergelijk CRvB 7 augustus 2013, $A B$ 2013/328, m.nt. Bröring; CRvB 26 juni 2013, $A B$ 2013/266, m.nt. Bröring. 